The jaundice began to fade inmediately after the operation, and at the end of six weeks had all disappeared except a slight yellow tinge upon the abdomen.

I went out of town on the 1st of April, six and a half weeks after the operation. He was then wearing the small tube, but was up and dressed. Dr. F. K. Paddock took charge of him during my absence. On my return on the 13th of May, Mr. B. met me at the station, looking well and very happy. Since then he has been well, though not very strong. He has had regular bilious stools, no pain, no jaundice and has gained flesh.

$\triangle$ CASE OF TOTAL OBLITERATION OF THE CESOPHAGUS TIIROUGHOU'T 'THE GREATER PART OF I'TS COURSE, OF DOUBTFUI ORIGIN; EXTERNAL CESOPHAGOTOMY AND A'T'TEMP'TS A'T DILA'TA'TION ; IDEA'TH. ${ }^{1}$

\author{
BY MAURJCH Ji. JHCHARJBON, M.D., \\ Surycon to the Massachusctts General Iospital.
}

G. C., three years of age, was sent to me at the Massachusetts General Hospital by Dr. George H. Francis, of Brookline, on July 1, 1891 .

Family history good. 'The child was perfectly well until last January, when he began to bave difficulty in swallowing food. At first solids, and then liquids, were with difficulty kept down. He could swallow liquids, but they were immediately regurgitated. At other times he could swallow and keep them down. 'This state of things has continued to the present time. One duy nourishment will not be retained at all, and the next day perhaps several quarts of milk will be swallowed and kept down. The child is emaciated and restless, otherwise not remarkable. At this time there was no history given of any possible local cause, such as the accidental swallowing of any burning or other irritating fluid.

On the 21st of July, having been under observation three weeks and no matorial change having taken place, he was discharged on account of an outbreak of scarlet fever in the ward.

On the 27th of July, 1891, he was re-admitted. Since leaving the hospital the littlo boy has not been able to swallow anything. Re-enters very emaciated and with a feeble and rapid pulse. Put at once on nutrient enemata and inunctions of cod-liver oil.

On the 29 th, under ether anxesthesia, an incision was made in front of the sterno-mastoid muscle on the left side, and the cesophagus was quickly exposed just below the level of the thyroid cartiluge. At this point it was normal in appearance and in culibre. The sides of the incision were grasped with retractors, and the caual exposed down to the level of the sterno-clavicular articulation, where a firm, fibrous stricture was encountered. It was impossible to find an opening into this stricture with the smallest urethral instrument. At one time it seemed as if a passage had been found, and through this was passed a filiform bougie. The opening was gradually dilated until it would admit the end of a small gum-elastic catheter. After very careful manipulation, the instrument was passed into what was thought to be the stomach. It was noticed immediately that air entered and was expelled from the mouth of the catheter with the movements of respira-

1 Iead beforo tho Boston Society for Medical Improvement, November 23,1891 . tion. It seemed probable that this was air passing to and from the stomach. After very careful observation of this unexpected phenomenon, a small quantity of milk and brandy was injected through the catheter into what was supposed to be the stomach. 'The child did not rally well after the operation, and died that same afternoon.

At the autopsy it was found that the ocsophagus had become entirely obliterated, from the level of the sternoclavicular articulation to the cardiac orifice. It was impossible to pass any instrument whatever through the canal. The catheter had made a false passage to the right into the pleural cavity into which the milk and brandy had been injected.

'This very unusual case presents certain features of great interest. It did not seem to me possible that this could be a congenital stricture of the cesophagus, because the onset had been quite sudden, and there had been no history of difficulty in deglutition up to the third year of the child's life. I therefore, some time before the operation, investigated the possibility of the closure being due to some corrosive action. I made careful inquiries, but was unable to find any ground for the belief that the child had swallowed anything injurious. Nevertheless, I did find that the first attack catme on suddenly.

The operation demonstrated clearly the feasibility, in children, of exposing oesophageal strictures situated five inches below the level of the incisor teeth. 'The upper end of the stricture was brought into view with the greatest ease. It was possible to hold back the sides of the ocsophagus and to search for the upper orifice without any difficulty whatever. In spite of all the care that $I$ could use in the passage of bougies and in the introduction of the catleter, the false passage was made. It would be impossible to use any force whatever in dilating a supposed stricture without the greatest danger of making a false passage. Unless the eye of the surgeon is upon the point of the instrument so as to guide it with absolute knowledge, the slighest force is sufficient to cause a lateral deviation into the pleura or into the posterior mediastinum. I was not conscious at any time of usingwany but the very gentlest manipulation.

In a case of this kind there is little to regret in the fatal termination. 'The only other course would have been a gastrostomy. I think no one would advocate such an operation in a child of three. Life, certainly, would not be worth living were it necessary always to employ this means of feeding.

I would advocate the use of external vesophagotomy for the relief of annular strictures situated within reach of the finger after an opening has been made through the neck. It is quite possible, as I have already shown, to reach with the finger as far as the arch of the aorta. I do not believe that it is justifiable to attempt any radical dilatation of benign strictures situated within reach of the finger, without first exposing the parts by the external incision. No degree of force sufficient to dilate thoroughly a stricture can safely be used through the mouth. In the case of this child, had I found a narrow stricture, I should have been tempted to excise the ring and unite the ends of the tube in a manner similar to that used in circular enterorraphy.

One other point to be noted is the importance of operating early. I have no doubt that in this case the chances of recovery were greatly diminished by the 
four weeks' delay which I employed in studying out the case. During that time the child failed very much indecd. Although I do not believe that it was possible for this child to recover under any circumstances, yet had the conditions been otherwise, I an confident the delay would have had an unfuvorable influence on the result.

\section{Elinical द्d}

\section{A CASE OF IIYIROPHOHIA.}

BY GARDNRR C. PHEleCle, M.J., OF ASHLAND, MASS.

Anours seven o'clock on the morning of July 14, 1891 , three children living in the south part of the town of Ashland, Mass., were savagely bitten by a Scotch collio dog weighing about sixty pounds, who seemed to be "rumning amuck" in attempting to bite evory one he met in his pathway. He evidently was the same dog that bit a man in South Framingham about five o'clock on the same morning. Counting each tusk hole and each tusk lacoration a bite, we found that Lizzic, aged eloven, was bitten in threo places; Mollie, aged seven, was bitten in twenty-one places; and the little brother Myron, aged tive, was bitten in nineteen places. Of these three children Lizzie, the oldest, presented only two bites on the left arm above the elbow, and one bite on her left cheek. Mollie, who was used the worst, presented severe wounds and lacerations on both legs bolow the knees; for she and her little brother were barefooted when attucked. 'The boy Myron also had very ugly wounds on his logs und left arm. On these two younger children about half of the bites consisted of a tusk hole from one-third to two-thirds of an inch deep, and the other marks of violence were deep tenrs or lacerations any where from one inch to two inches long. Some of these fissures were so deop that the flesh rolled out, presenting ragged, ugly, gaping wounds.

The patients were seen by the writer about thirty minutes after the attack of the dog. The wounds were cauterized with a thirty-three per cent. solution of carbolic acid. 'The father was advised to take these children to the Pasteur lnstitute in New York for treatment, immediately; for the dog was presumed to be rabid. 'The most certain way of ascertaining whether or no tho dog was rabirl, would naturally have been to have caught and placed him in confinement. But he was in altogether too dangerous a condition to allow of this. He ovidently was laboring under an extreme degreo of delirious excitement, and was ready, and even eager, to attack and bite every living thing that came in his way. After his attack on the children he made a fierce onset upon a teamster in the yard of the Adums farm, whereupon he was beaten to death with clubs by tho attendants about the place. 'The animal was buried without the writer having an opportunity of seeing the body. But those who did see it, said ho was quite thin of tlesh. 'They opened his stomach, and found in it $a$ dozen or more yravel-stones about the size of cherry pits, perhaps two tablespoonfuls of road-dirt, soine grass, and some pieces of biscuit. Before he was killod ho was frothing, they said, at the mouth and "furiously excited." All these circumstances seemed to indicate that the animal, without doubt, was rabid.
Just forty-eight hours after these children were bitten, they had reached New York, aud had taken their first inoculation at the Pasteur Institute. The special methods in this treatment are well understood by us all, and need not be described here. 'These children were treated by what we would understand as the simple Pasteur inoculative method. 'The inoculations or injections were practised once each day. The term of treatment continued eighteen days. During the treatment the patients had no particular symptoms of any kind. On Saturday morning July 31 , the children received their last and eighteenth inoculation, and the same day started for and reached home at eleven o'clock at night.

On the Tuesday morning following (August 4th,) Lizzie, the oldest girl, was taken ill with nausea and vomiting, and was quite feverish and rostless. Her nausea and vomiting continued until the next day, when she began to improve, and by the night of August 5 th was well again. She had no physician to attend her. What was the nature of her indisposition, cannot be known. Whother a recently inoculated person can present inceptive symptoms of the rabid state soon recovered from, is not now exactly known; but it is something to bo looked for in future observations.

'The next day after Lizzio recovered, 'Thursday afternoon, August 6th, and five days after ho had taken his last inoculation at the Pasteur Institute, Myron, the little five-years-old victim, was also taken sick. His first symptoms were moderate feverishness, nausea and vomiting. There was a slight degree of hebetude in his demeanor. Frilay, the next day, the nausea and vomiting continued. He was chilly and feverish by turns. Itis face was alternately flushed and pale. $A$ physician thus far had nol been called to him, for the parents supposed he was probably sick like his sister, and would soon be well again. But Saturday morning, as he appeared much worse, the writer was summoned, when he noted the following symptoms : Temperature $100^{\circ}$, pulse 105 . 'The pupil of the left eye was considerably dilated. 'There was a constant twitching at the angles of the mouth, and a slight jerking of the fingers of both hands from a spasmodic action of the muscles of the forearms. The tongue was slightly coated. He did not complain of headuche. To a close observer a slight, but somewhat peculiar staring expression was noticable in his eyes. His countenance for the most part was pale. By Saturday afternoon he was delirious at times, but in the intervals wa quite rational. The stomach at this time could not retain much food or drink. He had much difficulty in swallowing liquids, yet could force some down after much effort. His eyes were sometimes bright and glistoning, and at other times they appeared dull and expressionless.

On Sunday morning the patient was much worse in every way. All of the symptoms had increased in intensity. The temperature, however, was only $100.5^{\circ}$, but the pulse was 130 per minute. The skin would be flushed for eight or ten minutes, and then for about the same length of time be quite pale. An eruption appeared on the front part of the body, and on the left cheek, - more marked in these localities, but also faintly to be seen on the back and other parts of the body. It had somewhat the appearance of urticaria, but the patches were larger. Some were crescentic in shape, others were oval, while others were of irreg- 